\title{
Informed Trading and the "Leakage" of Information
}

\author{
Aditya Goenka \\ (University of Essex) \\ December 2000
}

\begin{abstract}
This paper, in a Shapley-Shubik market game framework, examines the effect of "leakage" of information: private information becoming available to uninformed traders at a later date. We show that (a) If information acquisition by the informed traders is costless, this leads to faster revelation of information; (b) If information acquisition is costly, there may be no acquisition of information; (c) Information leakage leads to a fall in value of information and hence, increases the incentive for informed traders to sell the information.
\end{abstract}

KEYWORKDS: Informed trading, insider trading, strategic market games, information revelation, arrival of information, market efficiency.

JEL Classification Numbers: D82, C72, G14, D51, D84.

This paper was finished while I was visiting the CIE at ITAM, Mexico. I would like to thank ITAM for its hospitality. This paper has benefitted from comments of seminar participants at Erasmus, Swansea, and Essex, especially Abhinay Muthoo and Tridib Sharma.

Contact: Department of Economics, University of Essex, Wivenhoe Park, Colchester CO4 3SQ, U.K. Tel: (+44) 1206 872765, Fax: (+44) 1206 872724, Email: goenka@essex.ac.uk 


\section{Introduction}

This paper examines the effect of 'leakage of information,' i.e., private information becoming available to uninformed agents, on strategic market trading in a dynamic context. In existing strategic models of trading under asymmetric information, the set of informed traders, whether single or multiple, is held fixed over the different rounds of trading, and the uninformed may try (or may not if they are 'noise traders') to infer information from the trades and equilibrium outcomes. In these models the informed can weigh the costs of the liquidity effect and the information effect and can control how much information is revealed through prices. However, in many situations of interest, the informed cannot be sure that information that they have tried to keep private through uninformative trades may not become public at a later date, or the uninformed can become informed through mechanisms other than inferring information from equilibrium outcomes. Thus, the set of informed traders may grow over a period of time. We show that this phenomenon may make the prices incorporate the private information at a faster or slower rate depending on how the information acquisition by the informed is modelled, i.e., is it costless or costly. In the latter case, one may end up in a situation similar to the Grossman-Stiglitz paradox. In addition, we also examine the incentives for the informed to sell their own private information to the uninformed when there is a potential of information leakage.

The study of the effect of private information on trading has been an important topic in economic theory and finance. The early literature on Rational Expectations Equilibria examined the role of prices in the aggregation of information: to what extent do the prices reveal the private information of the agents. The literature in finance, especially that of market microstructure, examines the incentives of agents to trade in the presence of asymmetric information when they recognize that their own actions affect market prices. However, the literature largely takes the set of informed agents to be fixed, and allows for no information leakage over the trading. 
In modelling the phenomenon of strategic trading and information leakage, we use the strategic market game a la Shapley-Shubik (Shapley [20], Shapley and Shubik [21]) as the underlying game. In this framework, the agents act strategically taking into account how their actions affect equilibrium prices, and hence, account for their own actions revealing information. This avoids the problem of the informed agents acting 'schizophrenically,' (see Hellwig [10]) i.e., inferring information from prices while not taking into account the effect of the informativeness of their own trade. In the formulation of the model we follow Dubey, Geanakoplos and Shubik [5]. Thus, we also do not allow agents to condition their trades on the information contained in current prices (see also Milgrom [19], and Hellwig [11]). If we are to think of trading taking place in real time, then this sequence of trading is the appropriate one. Adopting this formulation also avoids the problem associated with revealing Rational Expectations Equilibria first pointed out by Beja [3].

There are several other formulations of strategic trading that have been advanced, such as the models of Glosten and Milgrom [8], Kyle [16], Easley and O'Hara [6], Jackson [13], etc. We choose to work with the market game for three reasons. The first is tractability. The nice linear structure of the Kyle [16] model is no longer guaranteed once the market-maker has to update beliefs, taking into account that the set of informed traders is evolving over time. In the paper, we restrict to presenting examples, not because the general game is difficult to solve, but because the key insight is cleanly seen in examples which have relatively simple solutions. These examples are robust and can be generalized. The second is that we do not want to introduce noise traders. In our framework, every one is fully rational, except that some are informed and some are uninformed. Thus, if in our framework the price is non-revealing it is not due to noise or some configuration of parameters, but because of equilibrium behaviour. In addition, the welfare effects on all agents (see Spiegel and Subrahmanyam [22]) can be analyzed. Thirdly, this framework is flexible enough that a wide variety of different configurations - costly and costless information, storage of commodities, 
the role of short-selling, bankruptcy, etc., can be handled in the same model.

The literature on strategic informed trading (e.g., the market microstructure literature starting from Kyle [16] (also see Madhavan [18] for a survey; Dubey, Geanakoplos and Shubik [5], Jackson [13])) focusses on the case where the informed, who could be one or more (for a static model see Kyle [17]), know they are the only informed traders and trade taking into account the information revelation through prices. There are two effects which they trade off - liquidity and informativeness. Depending on the formulation of the model, there can be fast revelation of prices (e.g. Foster and Viswanathan [7], and Holden and Subrahmanyam [12]) or slow revelation of prices (e.g. Kyle [16]). However, these models abstract away from one important consideration - there is no change in the set of informed agents over time. This is not satisfactory as in any market, the informed cannot be certain that they will continue to be the only agents who are informed - if someone leaked the information to one, how can he be sure that it will not be leaked to someone else in the future. This paper focusses on how this affects the behaviour of the informed agents.

There are three problems we address in this paper. First, if the information is costless, how does the potential leakage of information affect incentives to use information at early stages of trading. In contrast to the intuition of Dubey, Geanakoplos and Shubik [5] (in the market game framework) and Kyle [16] (in a model with a market maker), the informed traders will want to use their information quickly. This will be the case, whether they may have wished to wait to use information due to their preferences, or whether they may have wished to wait to accumulate their stocks of commodities and assets to trade at a later date. Secondly, if information is costly, how does the potential leakage of information at a later date affect incentive to purchase information in the first place? In contrast to Jackson [13] traders may not want to purchase the information. Thus, one is back to the paradox of Grossman and Stiglitz [9]. Thirdly, how does the potential of arrival of information affect the incentive of an informed agent to sell the information? Here in contrast to Admati and Pfleiderer [1], 
informed agents will want to sell information not due to the motive in their paper, but to a different motive.

As the evidence finds that 'buys' move prices more than 'sells' (see Chan and Lakonishok [4] and Keim and Madhavan [15]) we focus on the case of informed buyers and treat selling as non-information based. These papers also point out that when agents trade on short lived information, they tend to prefer market orders. In fact, in the market upto $90 \%$ of orders are market orders. In the market game formulation the bids of the agents are best interpreted as such market orders. One can also interpret the informed traders in our model as institutional traders who are long lived as opposed to the uninformed traders who are private traders and in the market for only a short time. The results also help explain price increases before the information is announced in the market (see Barclay and Warner [2] for the case of tender-offers).

In the paper we outline the general formulation of the game. Then to make the results stark we illustrate the phenomena through a series of examples. These examples are variations of those in Dubey, Geanakoplos and Shubik [5]. In looking at the examples it will be clear that the results are robust and do not depend on the special functional forms assumed.

\section{The Model}

We define a general market game following Dubey, Geanakoplos and Shubik [5] with one essential difference: the evolution of the information partitions. There is the possibility that the information can leak to some uninformed traders so that at a later date they become exogenously informed. This is a game without storage of commodities.

There are a $N=N^{I}+N^{U, 1}+N^{U, 2}<\infty$ traders indexed by $n$, and two periods, $t=1,2$. The $N^{U, 1}$ traders live in the first period and $N^{U, 2}$ live in the second. The 
reason for having two generations is that consumption takes place at the end of each period, and we do not want information revelation from this act. Alternatively one can have one generation but require all consumption to take place at the end of period 2 . The $N^{I}$ traders live for both the periods. There are a finite states of the world, $s \in S$, which are realised before trading in the first period and this state remains the same in the second period. For each agent $n \in N$ let $I^{n}$ be a partition of $S$ representing the initial information of $n$. If the state of nature is $s$ then each trader knows the set $I^{n}(s)$ in his information partition that contains $s$. The traders $n \in N^{I}$ are informed, i.e., $I^{n}(s)=\{s\}$ for $n \in N^{I}$. There are a finite number of commodities $L$ in each state and period. The $N^{I}$ traders have a utility function over their consumption set. The utility function, $u^{n}$ is twice-continuously differentiable, concave, and monotonic. The $N^{U, t}, t=1,2$ uninformed traders in each period each have utility functions with the same properties as above. Each trader has an endowment $e^{n, t}$ in the periods in which he is alive, and the endowment is measurable with respect to their information set.

The game can be thought of as an extensive form game. Nature moves by selecting a state $s$. In the first period, at each node, $n \in N^{I} \cup N^{U, 1}$ of the players move simultaneously given their information partitions. A move for each player at each node is a $2(L-1)$ dimensional vector of bids and offers $z^{n, t}=\left(b_{1}^{n, t}, \ldots, b_{L-1}^{n, t}, q_{1}^{n, t}, \ldots, q_{L-1}^{n, t}\right)$. The subscript denotes the commodity, the first argument of the superscript is the identity of the player, and the second argument is the period in which the trade is made, $t=1,2$. Each $b_{l}^{n, t}$ represents a quantity of the $L$ th good that is bid on commodity $l$, and $q_{l}^{n, t}$ represents a quantity of the $l$ th good that is offered for sale. Given a vector of moves for each trader, the market adds the bids and offers for each commodity, $b_{l}^{t}(z)=\sum_{n} b_{l}^{n, t}, i=1, \ldots, L-1$, and $q_{l}^{t}(z)=\sum_{n} q_{l}^{n, t}, i=1, \ldots, L-1$. It sets $p_{l}^{t}(z)=\frac{b_{l}^{t}(z)}{q_{l}^{t}(z)}$. If there are no offers, the price is zero. The consumers receive net trades

$$
y_{l}^{n, t}=\frac{b_{l}^{n, t}}{p_{l}^{t}}-q_{l}^{n} .
$$


In addition,

$$
y_{L}^{n, t}=\sum_{l=1}^{L-1} q_{l}^{n, t} p_{l}^{t}-\sum_{i=1}^{L-1} b_{i}^{n, t} .
$$

If there is no inventorying then players at node $s \in S$ consume the net trade plus the endowment at that node, i.e., $x_{l}^{n, t}=e_{l}^{n, t}+y_{l}^{n, t}$.

Each node $s \in S$ in period 1 leads to an infinity of successor nodes $(s, z, m)$ where $z$ is the collective play of the agents at node $s$, and $m$ indexes the number of generation 2 uninformed who have become informed. Thus, in node $(s, z, m)$ there will be a new generation of players, of which $m$ will be informed and $N^{U, 2}-m$ will be uninformed. In what follows we restrict $N^{U, 1}=N^{U, 2}$ and that that each generation trader is identical to the corresponding trader in the previous generation except that their information sets may be different. Denote the information set of these players by $I^{n, 2}$. These players refine the information observing prices, which may or may not convey any information, and there is a probability that they can become informed. Thus, let $\rho$ be a probability that one of these $N^{U, 2}$ players is leaked the information. Thus, the information set of player $n \in N^{U, 2}$ is with probability $\rho$ is the same as that of the informed players, i.e., $I^{n, 2}=s \vee p^{1}$ and with the complementary probability $1-\rho, I^{n, 2}=I^{n} \vee p^{1}$, where $p^{1}$ is the price realized in the first period of trading. As each of the $N^{U, 2}$ 'uninformed' traders can become exogenously informed before the second round of trading, the probability that $M$ of them are informed is given by $\left(\begin{array}{c}N^{U, 2} \\ M\end{array}\right) \rho^{M}(1-\rho)^{N^{U, 2}-M}$. The rules of the second round are identical to those of the first round.

A strategy of a player $n$ is to pick a move at each node in each period when he is active such that it is measurable with respect to his information set in that period. We also have the restrictions that $q_{l}^{n, t}(s) \leq e_{l}^{n, t}(s)$, for $l=1, \ldots, L-1$, and $\sum_{j=1}^{L-1} b_{j}^{n, t}(s) \leq e_{L}^{n, t}(s), t=1,2$. In other words, a trader cannot short-sell a commodity in any period, and the total bids for commodities must be less than or equal to the endowment of the commodity money. We analyse the Perfect Bayesian Equilibria of 
this game. As we are going to restrict oursevlves to situations where traders can be on only one side of the market, only buy or sell a commodity, there will be no loss in generality in looking at only the pure-strategy equilibria of the game.

\section{Example 1: Costless information}

We look at a simplified version of the game above. There are two time periods $t=1,2$. There is only one perishable good in each period in addition to the commodity money. There is no inventorying. There are two equiprobable states. In state 2 the good has no value. There are three types of traders: sellers (who can be either informed or uninformed) and informed and uninformed buyers. There is one trader of each type. ${ }^{1}$ Sellers have utility only for money, and have 20 units of the good in each period. Thus, it does not matter if the sellers are thought to be informed or uninformed as they will always want to sell their entire endowment. Informed buyers (I) are long-lived and have the utility function:

$$
u^{I}=\left[\frac{1}{2}\left(A \log x_{1}^{I, 1}+w_{1}^{I, 1}\right)+\frac{1}{2} w_{2}^{I, 1}\right]+\left[\frac{1}{2}\left(B \log x_{1}^{I, 2}+w_{1}^{I, 2}\right)+\frac{1}{2} w_{2}^{I, 2}\right] .
$$

where $x_{s}^{I, t}$ is the consumption of the good in state $s$ in period $t$, and $w_{s}^{I, t}$ is the consumption of 'money' in state $s$ and period $t$. In addition we restrict $A, B>0$.

The uninformed buyers (U) live for only one period. The uninformed buyers in the first period have utility functions:

$$
u^{U, 1}=\left[\frac{1}{2}\left(A \log x_{1}^{U, 1}+w_{1}^{U, 1}\right)+\frac{1}{2} w_{2}^{U, 1}\right] .
$$

The uninformed buyers in the second period have utility functions:

$$
u^{U, 2}=\left[\frac{1}{2}\left(B \log x_{1}^{U, 2}+w_{1}^{U, 2}\right)+\frac{1}{2} w_{2}^{U, 2}\right] .
$$

\footnotetext{
${ }^{1}$ This can be generalized to an equal finite, number of traders of each type.
} 
The buyers have zero holdings of the good, and $M$ units of 'money' in each period.

The informed know the true state while the uninformed do not know the true state. Thus, their information partition consists of the two states. While, the uninformed in the first period cannot use the information which may be revealed by the prices, the uninformed in the second period can use information contained in past prices.

\subsection{Case 1: No leakage of information}

To analyze the game we proceed as follows. First, we examine the optimal behavior of the two buyers in the second period, depending on whether both are informed (whether the 'uninformed' acquired the information through information leakage, or from past prices) or one is informed and the other uninformed. Note that in the second period the informed will always choose to use the private information if it has remained as such. Then, we look at the behavior of the two traders in the first period in isolation. The informed while trading (against the uninformed) has to weigh the payoff derived from first period trades against the informational impact of the trades. Thus, in the third step, the informed in the first period computes overall payoff of adopting a particular strategy taking into account the informational impact of trading in the first period, taking as given the optimal plays in the second period. The Perfect Bayesian Equilibrium will be that strategy which gives the highest equilibrium payoff to the Informed taking into account the informational impact of their trades. As the 'Uninformed' operate in only one period, they ignore any intertemporal informational effects. The second generation of the 'Uninformed' do perform Bayesian updating, but if the Informed has chosen to adopt a non-revealing strategy, the priors will not be refined. The method of solving the game has taken sequential rationality into account.

Given information partition, in the second period, each buyer selects how much to bid for the commodity. For the Informed $b_{s}^{I, 2} \in[0, M]$, where the subscript $s$ denotes 
the state $s=1,2$. As there is no gain from with-holding information in the last period, let $b_{1}^{I, 2}=b^{I, 2}$ and $b_{2}^{I, 2}=0$. If the other player is Uninformed, then he is constrained to choosing a bid that is independent of the state, $b_{1}^{U, 2}=b_{2}^{U, 2}=b^{U} \in[0, M]$. The market aggregates bids and offers. Thus, $b_{s}^{2}=\sum_{i} b_{s}^{i, 2}$, and $q_{s}^{2}=\sum_{i} q_{s}^{i, 2}$. Given these, the price is determined:

$$
p_{s}^{2}=\frac{b_{s}^{2}}{q_{s}^{2}}
$$

The buyers receive net trades of the commodity:

$$
y_{s}^{i, n}=\frac{b_{s}^{i, 2}}{p_{s}^{2}}
$$

The consumption is the net trade of the commodity, and the endowment of money minus the bid, $w_{s}^{i, n}=M-b_{s}^{i, n}$.

First, consider the case that the Uninformed have remained as such. The second period pay off to informed trader is:

$$
\pi^{I, 2}=\frac{1}{2}\left(B \log \frac{b^{I, 2}}{p_{1}^{2}}+M-b^{I, 2}\right)+\frac{1}{2} M=\frac{1}{2}\left(B \log \frac{b^{I, 2}}{p_{1}^{2}}-b^{I, 2}\right)+M .
$$

For the Uninformed, the bidding is independent of state:

$$
\pi^{U, 2}=\frac{1}{2}\left(B \log \frac{b^{2}}{p_{1}^{2}}+M-b^{2}\right)+\frac{1}{2}\left(M-b^{2}\right)=\frac{1}{2} B \log \frac{b^{2}}{p_{1}^{2}}-b^{2}+M .
$$

Where $p_{1}^{2}=\frac{b^{I, 2}+b^{2}}{20}$ and $p_{2}^{2}=\frac{b^{2}}{20}$.

The equilibrium bids can be derived for the two agents can be obtained from the first order conditions as:

1. For $I: B b^{2}=b^{I, 2}\left(b^{2}+b^{I, 2}\right)$.

2. For $U: B b^{I, 2}=2 b^{2}\left(b^{2}+b^{I, 2}\right)$. 
Note there is always a trivial autarkic solution where there is no trade. We concentrate on the equilibrium where there is non-trivial trade. Suppose, $B=20$, then solve for $b^{I, 2 *}=8.28$ and $b^{2 *}=5.84$. Given this the allocations of the commodity are $x_{1}^{I, 2 *}=11.728, x_{1}^{U, 2 *}=8.272$. The Payoffs in period 2 are: $\pi^{I, 2 *}=20.368$, and $\pi^{U, 2 *}=15.286$

Now consider the case where both agents are Informed. In this case the payoff function to both is:

$$
\pi^{I, 2}=\frac{1}{2}\left(B \log \frac{b^{I, 2}}{p_{1}^{2}}-b^{I, 2}\right)+M
$$

The equilibrium bids can be computed as $b^{I, 2 *}=10$, and the payoff to both is:

$$
\frac{1}{2}\left(20 \log \frac{10}{20} 20-10\right)+M
$$

For both traders this is equal to 18.026 .

Now consider period 1 in isolation, ignoring the effect of trades on the revelation of information through prices. In a similar way as above one can calculate the payoffs within the period.

First, consider the case where the Informed chooses to act as such. Then we are in a similar situation to the first case above. The payoff functions for the two traders will look similar except that the coefficient will be $A$ rather than $B$. If we set $A=10$, then:

1. $b_{1}^{I, 1 *}=4.142, b_{2}^{I, 1 *}=0$, and $\pi^{I, 1 *}=10.234$.

2. $b_{1}^{U, 1 *}=b_{2}^{U, 1 *}=2.928$, and $\pi^{U, 1 *}=7.643$.

If the Informed chose to act as uninformed in the first period, i.e., choose a strategy of bidding an equal positive amount in each state, then the payoff in the first period for the two traders will be: 


$$
\pi^{U, 1}=\frac{1}{2} A \log \frac{b^{1}}{p_{1}^{1}}-b^{1}+M
$$

In equiliubrium, $b_{1}^{U, 1 *}=b_{2}^{U, 1 *}=2.5$, and $\pi^{U, 1 *}=\frac{1}{2} 10 \log \frac{2.5}{5} 20-2.5+M=9.013$.

Thus, payoff matrix in period 1 is:

\begin{tabular}{|c|c|c|}
\hline & Informed & Uninformed \\
\hline & & 10 \\
\hline
\end{tabular}

The payoff matrix in period 2 is:

$\begin{array}{lcc} & \text { Informed } & \text { Uninformed } \\ \text { Informed } & 18.026,18.026 & 20.468,15.286 \\ \text { Uninformed } & 15.286,20.468 & \end{array}$

In deciding the optimal strategy, the Informed has to take into account the informational impact of trading in the first period. If he chose to act as an informed trader in the first period, then while he would have a higher payoff in the first period, the information will be incorporated in the first period, and all will be informed in the second period. Alternatively, if the Informed chooses not to use the information in the first period, the first period payoff will be lower, but in the second period he will be the only informed trader.

Thus, Informed can compute their payoff with disclosure (trading like Informed in the first period), and payoff without disclosure (trading like an Uninformed trader in the first period).

1. Payoff with disclosure $=10.234+18.026=28.26$

2. Payoff without disclosure $=9.013+20.468=29.481$

Thus, the unique Perfect Bayesian Equilibrium has the Informed choosing not to disclose information in first period. 


\subsection{Case II: Leakage of information}

Now suppose that with probability $\rho$ the Uninformed can costlessly acquire information in period 2. The game otherwise is the same as before. To compute the equilibrium, all one has to do is take into account that if the Informed did not disclose information through trades, with probability $\rho$ in the next period the Uninformed will be informed as well, and with probability $1-\rho$ will remain uninformed. Thus, the Informed has to compute the payoff of non-disclosure and disclosure and choose the optimal strategy accordingly.

$$
\begin{aligned}
\text { Utility of non-disclosure } & >\text { Utility of disclosure } \\
9.013+(1-\rho) 20.468+\rho 18.026 & >10.234+18.026 \\
\frac{1.221}{2.442} & >\rho \\
0.5 & >\rho .
\end{aligned}
$$

Thus, if $\rho$ is sufficiently high then in the unique Perfect Bayesian equilibrium the Informed will not find it worthwhile to hide the information. The intuition is simple. While there is a gain to waiting (given by the coefficients of the utility function) it is negated by the fact that with probability $\rho$ there may be no informational privelege in the second period, and thus, the Informed buyer has an incentive to use the information at an early date.

\subsection{Note}

1. One can generalize this example to see that there will be a monotonic relation between the gain from waiting, $\frac{B}{A}$, and the probability of information leakage, $\rho$, for trade to take place at an earlier date, i.e., the higher is the gain from waiting the higher has to be $\rho$ to lead to early trade. 
2. This example is somewhat artificial in that we have forced a form of antidiscounting or a benefit from waiting $B>A$. If we have $B<A$, then the information will always be used in the first period. If we are to interpret the game as one where the traders consume at the end of the two rounds then the assumption of $B>A$ is consistent with costs of inventorying the consumption good.

3. In the fourth example we look at the case of costless inventorying where there is an endogenous gain from waiting.

\section{Example 2: Costly Information}

In this example we maintain the structure and details of the game in Example 1, except that the information acquisition is changed. The 'Informed' agent has the option to purchase the information before the first period of trading at a cost $\Delta$. Only they have the option to purchase the information. If the buyer chooses not to purchase the information before the first round of trading, the option lapses, and he does not have access to it before the second round. Thus, the acquisition of information is endogenous.

\subsection{Case I: No information leakage}

The 'Informed' buyer will find it worthwhile to purchase information if the cost of purchasing it is less than the gain from using it. The way the game has been structured, if the information is purchased, it will never be used in the first round of trading as $A<B$. The amount that he would be willing to pay is: Payoff when informed Payoff when not being informed. In the previous example, we have computed the first payoff to be 29.481, and the second payoff to be $9.013+18.026=27.039$. Thus if $\Delta<29.481-27.039=2.442$, the buyers who have the option of purchasing the 
information will exercise it. In this scenario, they will also have the incentive not to use the information in the first round of trading.

\subsection{Case II: Leakage of information}

Now suppose that with probability $\rho$ the Uninformed (only) can acquire before the second round of trading. One can either interpret it as the information is leaked to them costlessly with probability $\rho$, or that with probability $\rho$ the information is sold to them at a low cost such that they find it worthwhile to acquire the information if it is made available to them. From the viewpoint of the 'Informed' what is important is that in the second period with probability $\rho$ they face an informed rather than an uninformed buyer. The buyer who has foregone the option to purchase the information in the first period has no access to it.

We know from the previous example, that if $\rho<0.5$, and if information was costless, the Informed would not have disclosed information in period 1. Now, set $\rho=0.05$, and $\Delta=2.4$. We know that in the absence of information leakage, the 'Informed' would be willing to purchase the information at this cost. However, will they still purchase the information when there is information leakage?

The utility from purchasing information and not disclosing it in the first round of trading is: $9.013+0.95(20.468)+0.05(18.026)-2.4=26.9589$. The utility from purchasing and disclosing information in the first round of trading is: $10.234+18.026$ $-2.4=25.470$. If the buyer does not purchase the information in the first period then with a probability $\rho$ he is the uninformed and the other buyer is informed, while with probability $1-\rho$ both remain uninformed. The utility from not purchasing information: $9.013+0.95(18.026)+0.05(15.286)=27.024$.

Thus, even if there is a disadvantage to being the uninformed in the second period, its cost is outweighed by the cost of purchasing the information in the first place - as with probability $\rho$ the information is worthless in the second period. The 
unique Perfect Bayesian Equilibrium has no purchase of information in the first period. The scenario is somewhat similar to the example of Grossman and Stiglitz [9] where no one purchases the information when there is a potential gain to purchasing it. With a very high probability (in this example 0.95 ) the markets will not be informationally efficient as no one will acquire the information.

\section{$4.3 \quad$ Note}

1. One can generalize the example to obtain a monotonic relationship between $\rho$ and $\Delta$.

\section{Example 3: Sale of information}

So far the sale of information has not beem modelled. One would want to know that if the person with access to information had a choice to sell the information whether he would be willing to sell it, and how the incentive to sell the information is affected by the potential leakage of the information. Admati and Pfliederer [1] show that an 'Informed' agent may wish to sell information if he is risk-averse (to permit better risk-sharing amongst the informed).

Here we focus on the long-lived agent who is Informed and has to decide whether to sell the information. The structure of the game and parameters are the same as in Example 1.

\subsection{Case I: No leakage of information}

If the Informed sells information at $\operatorname{cost} \delta$ in period 1, the Uninformed agent will immediately use the information, and the information will become public in period 2. Recognizing this, the informed will also want to use the information in the first stage. Thus, there will be two Informed traders in the first period. In this case the 
first period-payoff function to each is:

$$
\pi^{I, 1}=\frac{1}{2}\left(A \log \frac{b^{I, 1}}{p_{1}^{1}}-b^{I, 1}\right)+M .
$$

The equilibrium bids can be computed as $b^{I, 1 *}=5$, and the payoff to both is:

$$
\frac{1}{2}\left(10 \log \frac{5}{10} 10-5\right)+M \text {. }
$$

For both traders this is equal to 9.013 .

What is maximal amount that can be charged for the information in period 1 by the Informed ? We have $0 \leq \delta \leq 9.013-7.643=1.37$. The total payoff to the informed buyer is: $9.013+\delta+18.026=27.039+\delta$.

If he does not sell the information, and there is no arrival of information, then payoff is: $9.013+20.468=29.481$. Thus, as the gain to waiting $(29.481-27.039$ $=2.442)$ is greater than the maximal amount that can be charged, he will not sell information. Will he want to sell the information in period 2? The maximal amount that can be charged is now $18.026-15.286=2.740$. The gain in payoff of being the only informed in the second period is $29.481-(9.013+18.026)=2.442$. Thus, the informed will want to sell the information in period 2 for a price $2.442<\gamma<2.740$. Even though the Informed does not benefit from the information while trading, the proceeds from its sale compensate the loss in informational advantage. As the traders are risk averse in this example the sale or non-sale of information is not being driven by risk-sharing considerations.

\subsection{Case II: Leakage of information}

We know that for these parameters, that if there is arrival of information with probability $\rho<0.5$, the Informed will not reveal information in period 1 through his trades. In this case, the payoff is: $9.013+(1-\rho) 20.468+\rho$ 18.026. Fix $\rho=0.45$, and then this payoff $=28.381$. However, now the informed will prefer to sell the information in period 1 at cost $\delta \in(1.342,1.37)$. 
What about selling the information in period 2, instead of period 1 ?

The most that Uninformed in period 2 would be willing to pay is $\gamma \geq 0$ such that:

$$
18.026-\gamma \geq \rho 18.026-(1-\rho) 15.286
$$

When $\rho=0.45$, then $0 \leq \gamma \leq 1.433$. The total payoff from not selling information in period 2 is 28.381 and the total payoff from selling information in period 2: 27.039 $+\gamma$. Again the informed will rather sell information at cost $1.352 \leq \gamma \leq 1.433$. The Informed will rather sell information in period 2 than 1 as in this case the possible surplus that can be extracted is higher.

Notice that in the case of information leakage, the value of the information declines. This is what causes the Informed to now find it worthwhile to sell the information in the first period, and also what causes the decrease in the price that can be charged for the information in the second period. This avenue is different from that in Admati and Pfleiderer [1], as it is not risk-aversion which is driving the result but the decrease in the value of the priveleged information.

\section{Inventories and arrival of information}

In the previous examples the gain to waiting was somewhat artificial. The coefficients of the utility functions exhibited 'anti-discounting.' We now consider a different scenario where the potential of storing (inventorying) the commodities leads to a natural gain to waiting. The structure of the game is different from that in the previous examples.

There are two time periods $t=1,2$. There is only one consumption good in each period in addition to the commodity money. Both the goods can be stored costlessly. However, the traders cannot borrow against the future. There are four 
equiprobable states, indexed by the subscript $s=1,2,3,4$. There are two types of agents, $\alpha$ (the buyers) and $\beta$ (the sellers).

The preferences are given by:

$$
u^{\alpha}=\frac{1}{4}\left(x_{1}^{\alpha, 1}+x_{1}^{\alpha, 2}\right)^{0.5}+\frac{1}{4}\left(\left(w_{2}^{\alpha, 1}+w_{2}^{\alpha, 2}\right) \frac{1}{2}\right)^{0.5}+\frac{1}{4}\left(w_{3}^{\alpha, 1}+w_{3}^{\alpha, 2}\right)^{0.5}+\frac{1}{4}\left(x_{4}^{\alpha, 1}+x_{4}^{\alpha, 2}\right)^{0.5}
$$

and:

$u^{\beta}=\frac{1}{4}\left(x_{1}^{\beta, 1}+x_{1}^{\beta, 2}\right)^{0.5}+\frac{1}{4}\left(\left(w_{2}^{\beta, 1}+w_{2}^{\beta, 2}\right) \frac{3}{2}\right)^{0.5}+\frac{1}{4}\left(\left(w_{3}^{\beta, 1}+w_{3}^{\beta, 2}\right) \frac{4}{3}\right)^{0.5}+\frac{1}{4}\left(x_{4}^{\beta, 1}+x_{4}^{\beta, 2}\right)^{0.5}$.

Thus, in state 1,4 only the good has utility, while in state 2,3 only the money has utility. Traders of type $\alpha$ can distinguish between odd and even states, and traders of type $\beta$ can distinguish between $s \in\{1,2\}$ and $s \in\{3,4\}$. The endowment of $\alpha$ is 20 units of money in each period for $s=1,3$ and 30 units of money in $s=2,4$. The endowment of $\beta$ is 20 units of the good in each period for $s=1,2$ and 15 units of the $\operatorname{good}$ in $s=3,4$.

Each of the traders participates on the markets on both the dates. Otherwise, the rules of the market game is exactly as that above.

\subsection{Case I: No arrival of information}

If the agents know the state of nature, there will be no exchange, as there are no gains from trade. This information can only be revealed through the trades. There are two possible scenarios.

1. Scenario 1: The agents trade in the first period, and there is no trade in the second. 
2. Scenario 2: The agents carry over their endowments to the second period, and trade in the second.

\subsubsection{Scenario 1}

In the first period the $\alpha$ agent maximizes:

$$
\operatorname{Max}_{b_{O}^{1}}, b_{E}^{1} \frac{1}{4}\left(\frac{b_{O}^{1}}{p_{1}^{1}}\right)^{0.5}+\frac{1}{4}\left(\left(30-b_{E}^{1}\right) \frac{1}{2}\right)^{0.5}+\frac{1}{4}\left(20-b_{O}^{1}\right)^{0.5}+\frac{1}{4}\left(\frac{b_{E}^{1}}{p_{4}^{1}}\right)^{0.5} .
$$

The $\beta$ agent maximizes:

$$
\operatorname{Max}_{s_{L}^{1}, s_{R}^{1}} \frac{1}{4}\left(20-s_{L}^{1}\right)^{0.5}+\frac{1}{4}\left(p_{2}^{1} s_{L}^{1} \frac{3}{2}\right)^{0.5}+\frac{1}{4}\left(p_{3}^{1} s_{R}^{1} \frac{4}{3}\right)^{0.5}+\frac{1}{4}\left(15-s_{R}^{1}\right)^{0.5} .
$$

One can derive the first order conditions and solve for the equilibrium. The equilibrium is given by (for the first period): $b_{0}^{1}=10, b_{E}^{1}=15, s_{L}^{1}=7.5, s_{R}^{1}=6.667$, $p_{1}^{1}=1, p_{2}^{1}=2, p_{3}^{1}=1.5, p_{4}^{1}=2$.

The total payoff for the two periods for $\alpha=4.031$ and the payoff for $\beta=4.732$. Note that in period 2 there is no trade and the agents keep their endowments.

\subsubsection{Scenario 2}

In the first period there is no trade and all the goods are stored till the second period. In period 2 the $\alpha$ agent maximizes:

$$
\operatorname{Max}_{b_{O}^{2}}, b_{E}^{2} \frac{1}{4}\left(\frac{b_{O}^{2}}{p_{1}^{2}}\right)^{0.5}+\frac{1}{4}\left(\left(60-b_{E}^{2}\right) \frac{1}{2}\right)^{0.5}+\frac{1}{4}\left(40-b_{O}^{2}\right)^{0.5}+\frac{1}{4}\left(\frac{b_{E}^{2}}{p_{4}^{2}}\right)^{0.5} .
$$

The $\beta$ agent maximize:

$$
\operatorname{Max}_{s_{L}^{2}}, s_{R}^{2} \frac{1}{4}\left(40-s_{L}^{2}\right)^{0.5}+\frac{1}{4}\left(p_{2}^{2} s_{L}^{2} \frac{3}{2}\right)^{0.5}+\frac{1}{4}\left(p_{3}^{2} s_{R}^{2} \frac{4}{3}\right)^{0.5}+\frac{1}{4}\left(30-s_{R}^{2}\right)^{0.5} .
$$


The equilibrium is now given by (for the second period): $b_{0}^{2}=20, b_{E}^{2}=30$, $s_{L}^{2}=15, s_{R}^{2}=13.33, p_{1}^{2}=1, p_{2}^{2}=2, p_{3}^{2}=1.5, p_{4}^{2}=2$. The payoff for $\alpha=4.176$ and the payoff for $\beta=5.239$.

Thus, the unique equilibrium has trade only in the second period.

\subsection{Case 2: Leakage of information}

Now suppose that with an exogenous probability $\rho$ both the agents can acquire information (costlessly) before trading in period 2 of the true state of nature, i.e., it becomes public knowledge what the state is. Now the traders will have to reconsider the payoff from waiting. With probability $(1-\rho)$ the payoff is the same as above. However, with probability $\rho$ there is no-trade (as both are informed) in period 2. The payoffs for both, in this case, are equal to: 2.95 . Thus, if $(1-\rho) 4.176+\rho 2.95<4.031$,

or $\rho>0.118$, the agent 1 will trade in period 1 . For this example, agent 2 would rather have waited till period 2 for $\rho \leq 0.393$.

\section{Conclusion}

The efficient market hypothesis can be broken up into two parts (Jackson and Peck $[14]:$

1. Prices reflect all available information.

2. Uninformed do not lose due to informational disadvantage.

We see from the examples above that in the case of costless information:

1. If there is no information leakage the Informed may not disclose information in period, so that (1) and (2) fail. 
2. However, if there is a potential for Uninformed to acquire information at a later date, then prices are likely to be revealing so (1) is true, but not (2).

Thus, the potential for information leakage forces early disclosure of information.

In the case of costly information:

1. If there is no information leakage, then agents will want to purchase costly information, so that (1) and (2) fail.

2. However, if information can become available at a later date with a very low probability, then no one will want to pay to acquire the information, so that (1) can fail, but (2) may not.

Thus, there is a difference of the informativeness of prices depending on whether information is costly or not. In practice, acquisition of priveleged information is costly. However, often people choose not to acquire this information. In part, it is due to the intuition of the examples, there is a chance that the information may become useless before it can be used, thus, decreasing the attractiveness of acquiring the information. The fact that prices are not informationally efficient is not due to the revelation through prices as agents take into account that their trades will reveal their private information, but due to the channel pointed out above. This is also what drives the incentive to sell information rather than keep it exclusive and use it in trading. 


\section{References}

[1] Admati, A., and P. Pfleiderer (1988) "Selling and trading on information in financial markets," American Economic Review 78, pp. 96-102.

[2] Barclay, M. and J. Warner (1993) "Stealth trading and volatility: Which trades move prices," Journal of Financial Economics 34, pp. 281-306.

[3] Beja, A. (1977) "Limits of price information in market processes," Working paper 61, Research Program in Finance, University of California, Berkeley.

[4] Chan, L.K.C. and J. Lakonishok (1995) "The behavior of stock prices around institutional trades," Journal of Finance 50, pp. 1141-1174.

[5] Dubey, P., J. Geanakoplos, and M. Shubik (1987) "The revelation of information in strategic market games: A critique of rational expectations equilibria," Journal of Mathematical Economics 16, pp. 105-137.

[6] Easley, D., and M. O'Hara (1987) "Price, trade size, and information in securities markets," Journal of Financial Economics 19, pp. 69-90.

[7] Foster, D., and S. Viswanathan (1990) "A theory of intraday variations in volume, variance, and trading costs in securities markets," Review of Financial Studies $\mathbf{3}$, pp. 593-624.

[8] Glosten, L., and P. Milgrom (1985) "Bid, ask, and transaction prices in a specialist market with heterogeneously informed traders," Journal of Financial Economics 14, pp. $71-100$.

[9] Grossman, S., and J. Stiglitz (1980) "On the impossibility of informationally efficient markets," American Economic Review 70, pp. 393-408.

[10] Hellwig, M. (1980) "On the aggregation of information in competitive markets," Journal of Economic Theory 22, pp. 477-498. 
[11] Hellwig, M. (1982) "Rational expectations equilibrium with conditioning on past prices," Journal of Economic Theory 26, pp. 279-312.

[12] Holden, C., and A. Subrahmanyam (1992) "Long-lived private information and imperfect competition," Journal of Finance 47, pp. 247-270.

[13] Jackson, M. (1991) "Equilibrium, price formation, and the value of private information," Review of Financial Studies 4, pp. 1-16.

[14] Jackson, M., and J. Peck (1999) "Asymmetric information in a competitive market game: Reexamining the implications of rational expectations," Economic Theory, pp. 603-628

[15] Keim, D.M., and A. Madhavan (1995) "Anatomy of the trading process: Emperical evidence on the behavior of institutional traders," Journal of Financial Economics 37, pp. 371-398.

[16] Kyle, A. (1985) "Continuous auctions and insider trading," Econometrica 53, pp. $1315-1335$.

[17] Kyle, A. (1989) "Informed speculation with imperfect competition," Review of Economic Studies 56, pp. 317-356.

[18] Madhavan, A. (2000) "Market microstructure: A survey," Journal of Financial Markets 3, pp. 205-258.

[19] Milgrom, P. (1981) "Rational expectations, information acquisition, and competitive bidding," Econometrica 49, pp. 921-944.

[20] Shapley, L. (1976) "Noncooperative general exchange," in "Theory and measurement of economic externalities (S.A.Y. Lin, Ed.), pp. 156-175. New York: Academic Press.

[21] Shapley, L., and M. Shubik (1977) "Trade using one commodity as a means of payment," Journal of Political Economy 85, pp. 937-968. 
[22] Spiegel, M., and A. Subrahmanyam (1992) "Informed speculation and hedging in a noncompetitive security market," Review of Financial Studies 5, pp. 307-329. 